\title{
Pengaruh Brand Image dan Kualitas Pelayanan terhadap Keputusan Pembelian Jasa J\&T Express
}

\author{
Dani Adiatma \\ Universitas Garut \\ adiatmadani@uniga.ac.id
}

\begin{abstract}
Abstrak
Dalam menghadapi persaingan bisnis jasa pengiriman barang yang semakin ketat mendorong setiap perusahaan jasa untuk mempersiapakan diri sebaik mungkin untuk mempertahankan eksistensinya dalam menghadapi persaingan antar perusahaan sejenis lainnya untuk menarik dan mendapatkan keputusan pembeli agar mampu berhasil dalam menjalankan usaha. Terutama penerapan strategi pemasaran yang tepat yang mampu bersaing dengan perusahaan jasa lain. Tujuan penelitian ini yaitu untuk mengetahui pengaruh brand image dan kualitas pelayanan terhadap terhadap keputusan pembelian jasa J\&T Express Garut. Teknik Analisis yang digunakan yaitu analisis regresi linear bergandamelalui bantuan software SPSS versi 16. Sampel yang digunakan sebanyak 50 responden. Hasil penelitian menunjukan bahwa brand image dan kualitas pelayanan berpengaruh terhadap keputusan pembelian jasa berpengaruh positif dan simultan terhadap keputusan pembelian jasa J\&T Express. Brand image berpengaruh positif secara signifikan terhadap keputusan pembelian jasa. Kualitas pelayanan berpengaruh positif secara signifikan terhadap keputusan pembelian jasa.
\end{abstract}

Kata kunci: Brand Image, Kualitas Layanan, Pilihan Pembelian.

\begin{abstract}
In the face of increasingly fierce competition in the shipping service business, it encourages each service company to prepare itself as best as possible to maintain its existence in the face of competition between other similar companies to attract and get buyers' decisions in order to be able to succeed in running a business. Especially the implementation of the right marketing strategy that is able to compete with other service companies. The purpose of this study was to determine the effect of brand image and service quality on purchasing decisions for $J \& T$ Express Garut services. The analysis technique used is multiple linear regression analysis with the help of SPSS version 16. The sample used was 50 respondents. The results showed that brand image and service quality had a positiveand simultaneous effect on purchasing decisions for $J \& T$ Express services. Brand image has a significant positive effect on service purchase decisions. Service quality has a significant positive effect on service purchasing decisions.
\end{abstract}

Keywords: Brand Image, Service Decision, Service Quality. 


\section{Pendahuluan}

Persaingan antar organisasi pengirim kargo sangat erat. Khususnya organisasi administrasi seperti JNE, Tiki, Pos Indonesia, yang selama ini memiliki brand image yang cukup baik dan kesan positif di benak masyarakat cukup lama, memilih pilihan pembelian yang sebagian besar berpusat pada jasa transportasi tersebut. Sementara itu, J\&T Express adalah sebuah organisasi bantuan yang masih baru, yang didirikan pada tahun 2015, sehingga J\&T Express tidak menonjol di kalangan masyarakat pada umumnya, dibandingkan dengan merek pesaing lainnya yang telah cukup lama dikenal. populasi umum. Untuk mengikuti dan mengembangkan citra citranya lebih jauh serta memiliki pilihan untuk menyaingi merek-merek sebelumnya, J\&T Express harus memiliki opsi untuk membuat dan memberikan kesan positif tentang citra merek tersebut sehingga pelanggan lebih yakin dan tertarik untuk menggunakan layanan administrasinya. Pelaksanaan metodologi yang tepat dan sesuai harus dilakukan oleh administrator organisasi. Manajer J\&T Express harus mampu berpikir seperti berada di posisi konsumen, karena dengan berada di posisi ini perusahaan bisa mengetahui apa saja yang dibutuhkan dan diperlukan konsumen agar mau dan tetap menggunakan jasa perusahaan. Semua jenis brand ditawarkan kepada konsumen dengan kelebihan yang dimilikinya serta diikuti dengan pelayanan terbaik untuk memenuhi kebutuhan dan memuaskan harapan konsumen oleh perusahaan

Selain brand image, kualitas pelayanan yang baik kepada konsumen juga merupakan bagian terpenting dalam menentukan sebuah keputusan dalam pembelian. Setiap konsumen pasti memiliki sifat yang kritis dalam memilih dan menentukan jenis perusahaan jasa mana yang akan digunakan sesuai dengan yang dibutuhkan dan dirasakan bagus. Tentu saja konsumen akan memilih dan menggunakan perusahaan jasa yang mampu melayani konsumen dengan baik, tidak membeda-bedakan konsumen, simpati dan sesuai dengan yang diharapkan konsumen. Begitupun sebaliknya, jika konsumen tidak merasa puas atau merasa tidak sesuai harapan dengan pelayanannya, banyak kemungkinan konsumen akan mencoba perusahaan jasa lain yang menurutnya sesuai dan menimbulkan rasa cocok dan pusa dihati konsumen. Ada beberapa yang menjadi ukuran dalam kualitas pelayanan yaitu, perusahaan memiliki sarana dan prasarana yang baik dengan kebersihan yang terjaga, pegawai yang melayani memiliki kehandalan serta kecepatan dalam bekerja, memiliki kemampuan menyampaikan informasi yang jelas, cepat, lengkap dan tepat, benar-benar mengkhawatirkan pembeli, dan pekerjanya dapat memberikan kenyamanan dan keamanan kepada pembeli dalam memenuhi kebutuhan mereka.

J\&T Express adalah organisasi bantuan paling muda yang tidak jauh berbeda dengan organisasi yang sudah berdiri sejak lama seperti Pos Indonesia, JNE, Tiki, dan lain-lain. Terlepas dari kenyataan bahwa J\&T Express perusahaan baru, dalam waktu yang sebentar perusahaan ini sudah banyak dikenal bahkan diterima oleh masyarakat dengan cukup baik. Sejak bulan Agustus 2015 pertama kali J\&T Express bergerak di pasar logistik, persaingan antara sesama perusahaan sudah mulai ketat. Perusahaan ini memiliki keunggulan yang tidak bisa dianggap biasa. Pada kurun waktu setahun, J\&T Express telah hadir di seluruh wilayah Indonesia, dengan kerangka kerja yang baik yang cocok untuk menyampaikan administrasi yang cepat, aman, dan mengurangi kesalahan spesialis yang dapat mengurangi sifat administrasi mereka. Karena perjuangan organisasi saat ini, organisasi tersebut telah diberikan Penghargaan Top Brand untuk Layanan Ekspedisi di usia organisasi yang masih muda. Selain itu, penghargaan ini akan terus berlanjut hingga gelar ketiga di tahun 2020. Berikut adalah hasil dari pemberian Top Brand Award untuk ekspedisi tahun 2020, yang dapat dilihat pada tabel 1 di bawah ini: 
Tabel 1 : Hasil top brand award khusus jasa ekspedisi (2020)

\begin{tabular}{ccc}
\hline MEREK & TBI & TOP \\
\hline JNE & $27.3 \%$ & TOP \\
\hline J\&T & $21.3 \%$ & TOP \\
\hline Tiki & $10.8 \%$ & TOP \\
\hline Pos Indonesia & $7.7 \%$ & \\
\hline DHL & $\mathbf{4 . 1 \%}$ &
\end{tabular}

Sumber: http://www.topb randaward.com

Dari data Top Brand Award diatas menunjukan bahwa dalam kurun waktubeberapa tahun, J\&T Express $21.3 \%$ dapat mengungguli perusahaan jasa kuriryang telah lama berkecimpung seperti TIKI 10,8\% dengan unggul tingkat persentase 10,5\% dan perusahaan BUMN yaitu Pos Indonesia $7,7 \%$ dengan tingkat persentase $12,6 \%$. Namun masih dibawah JNE yang unggul dengan jumlah persentase sebanyak $27,3 \%$.

\section{Tinjauan Pustaka}

\subsection{Brand Image}

Brand atau merek merupakan sebuah tanda, simbol, julukan, sebuah rencana atau campuran dari mereka yang mengenali barang-barang pedagang dan memisahkannya dari barang-barang pesaing lainnya, dan menjadi salah satu faktor utama dalam menghadirkan, memajukan, dan menawarkan suatu barang dalam kegiatan pemasaran yang tidak akan lepas dari citra merek (Chandra dan Santoso, 2019). Brand image memperlihatkan sifat luar yang menjadi kelebihan dari suatu produk atau jasa termasuk cara di mana merek berusaha memenuhi kebutuhan psikologis atau sosial pelanggan (Kotler dan Keller, 2016).

Menurut Endriani (2020), untuk mengukur suatu brand image bisa menggunakan indikator Citra Pencetus (Corporate Image). Citra pencetus adalah sebuah asosiasi suatu produk barang atau jasa tertentu yang membuat sebuah pandangan yang menarik kepada konsumen agar tertarik membeli atau menggunakan barang atau jasa yang ditawarkannya. Hal yang perlu dijaga dalam meningkatkan kemampuan serta jaringan perusahaan adalah sebagai berikut:

1. Terkenal/populer, sebuah perusahaan yang sudah banyak dikenal dan disukai banyak konsumen.

2. Inovatif, organisasi yang selalu melakukan lompatan ke depan/perkembangan baru adalah organisasi yang dapat menyaingi para pesaingnya.

3. Area organisasi, di mana latihan bisnis terjadi dan aktivitas organisasi.

\subsection{Kualitas Pelayanan}

Kualitas pelayanan sebagai usaha untuk mewujudkan kenyamanan terhadap konsumen, agar konsumen merasa mempunyai nilai yang lebih dari yang diharapkan. Sehingga terbentuk pula citra yang baik di mata konsumen (Tjiptono, 2016). Kesadaran akan kualitas dimulai dari diidentifikasinya persyaratan-persyaratan konsumen sampai dimulainya gagasan konsep produk (jasa), bahkan setelah pengiriman kepada konsumen. Hal ini dilakukan untuk memperoleh umpan balik dan mendengar suara konsumen (Lupiyoadi, 2013). Menurut Endriani (2018) ada lima indikator kualitas pelayanan, yaitu: 
1. Bukti Aktual (Berwujud)

Bukti nyata menunjukkan kapasitas yang dimiliki organisasi untuk menunjukan keberadaanya kepada semua pihak diluar perusahaan. Gedung, peralatan yang digunakan sarana dan prasarana fisik lain yang dimiliki perusahaan, penampilan serta kemampuan para karyawan, dan keadaan lingkungan yang ada disekitarnya merupakan suatu bukti dari administrasi yang akan diberikan oleh organisasi sebagai spesialis co-op untuk pembeli.

\section{Keandalan (Keandalan)}

Keandalan adalah suatu kemampuan yang digerakkan oleh suatu organisasi untuk menawarkan suatu dukungan sesuai dengan apa yang telah dijamin atau disampaikan secara cepat, tepat, tepat dan dapat diandalkan.

\section{Ketanggapan (Responsiveness)}

Ketanggapan adalah suatu kemampuan yang harus dimiliki perusahaan mengenai kecepatan dan ketanggapan serta ketepatan dalam memberikan pelayanan kepada konsumen dengan disertai pemberian informasi yang tepat kepada konsumen (Mutia, 2018).

\section{Jaminan (Assurance)}

Jaminan adalah kemampuan yang harus digerakkan oleh setiap organisasi bantuan dengan memberikan jaminan barang atau jasa yang ditawarkan, tingkat informasi, moral dan kebiasaan para pekerjanya, serta kemampuan perwakilan organisasi untuk menciptakan kepercayaan dari pelanggan kepada organisasi.

\section{Simpati}

Simpati merupakan kemampuan yang harus dimiliki perusahaan dalam menunjukkan dan memberikan suatu perhatian dengan niat yang tulus, bahkan bersifat pribadi melalui pegawai yang diberikan kepada konsumen dengan tujuan untuk memahami apa yang menjadi keinginan dan kemauan konsumen.

\subsection{Keputusan Pembelian}

Keputusan pembelian menurut Kotler \& Armstrong (2014) adalah tahap dalam proses pengambilan keputusan pembeli di mana konsumen benar-benar membeli. Fase dalam interaksi dinamis pembelanja, di mana pelanggan benar-benar membeli produk atau jasa tersebut merupakan definisi dari keputusan pembelian. Tindakan yang dilakukan konsumen secara sadar dan disengaja dalam memilih salah satu pilihannya yang didasarkan atas keinginannya sendiri (Audina dan Murtani 2019).

Perilaku pembelian memiliki 4 jenis yang harus diketahui dilihat dari tahap keikut sertaan konsumen dan tahap perbedaan setiap merek antara lain perilaku pembelian sulit, perilaku ini memiliki 3 langkah proses yaitu:

1. Pembeli yang membeli barang atau administrasi harus meningkatkan kepercayaan tentang bantuan atau barang tersebut.

2. Pembeli yang membeli barang atau administrasi harus memperhatikan administrasi dan barang tersebut.

3. Pembeli yang akan membeli suatu barang atau administrasi memutuskan suatu keputusan dalam pembelian dengan hati-hati. 


\section{Metode Penelitian}

Metode Penelitian yang dilakukan oleh peneliti menggunakan strategi investigasi kuantitatif. Teknik kuantitatif adalah strategi eksplorasi yang digunakan untuk menyelidiki contoh atau populasi tertentu. Dalam memutuskan contoh dan mengambil contoh menggunakan strategi yang tidak teratur, penelitian kuantitatif digunakan untuk mengumpulkan informasi, seperti halnya teknik ilmiah yang memanfaatkan strategi kuantitatif sepenuhnya untuk menguji teori yang telah dibuat (Endriani, 2018). Review ini menggunakan strategi yang jelas, yaitu teknik pemeriksaan yang bertujuan untuk memberikan gambaran pilihan klien administrasi dalam keputusan pembelian di J\&T Express Garut.

\section{$4 \quad$ Hasil Penelitian dan Pembahasan}

Perusahaan J\&T terus mengalami perkembangan di usianya yang masih muda dan mampu menguasai pasar jasa di seluruh Indonesia kedua setelah JNE. Kemudian pada bulan Maret 2018 J\&T Express melakukan Ekspansi ke luar negeri yaitu di negara Malaysia dan Vietnam. Tujuan Ekspansi ini untuk memperluas jangkauan pengiriman barang yang menjangkau luar negeri. Selain itu, J\&T juga melakukan ekspansi ke negara Singapura pada bulan Juli 2019, Kamboja pada bulan September 2019 dan mampu meraih penghargaan Go Asean Champion 2019 Award.

\section{Variabel Brand Image}

sebagian besar responden memberikan jawabansetuju, dimana hasil terbanyak setuju terdapat pada item atau pernyataan ke-4 dan 5 yaitu Pengguna J\&T Express dapat digunakan di segala usia ( $<20 \mathrm{~s} / \mathrm{d}>41$ dan pengguna J\&T Express dapat digunakan di segala kalangan (kalangan bawah, kalangan menengah dan kalangan atas) sebesar $50 \%$ atau sebanyak 25 responden. Maksudnya banyak yang setuju bahwa penggunaan jasa ini tidak hanya untuk kalangan tertentu saja, semua kalangan bisa menggunakan jasa ini.

Hasil terkecil atau tidak setuju pada item atau pernyataan ke 6 yaitu J\&T Express dapat digunakan oleh pedagang sebesar $2 \%$ atau 1 responden. Berdasarkan data tersebut dapat disimpulkan bahwa sebagai jasa pengiriman J\&T Express dapat digunakan di segala kalangan (kalangan bawah, kalangan menengah dan kalangan atas) sehingga pelanggan tertarik untuk menggunakan jasa J\&T Express Garut Kota.

\section{Variabel Kualitas Pelayanan}

sebagian besar responden memberikan jawaban setuju, dimana hasil terbanyak setuju terdapat pada item atau pernyataan ke 8yaitu karyawan kerja cepat dalam melakukan tugasnya sebesar $56 \%$ atau sebanyak 28 responden. Hasil terkecil atau tidak setuju pada item atau pernyataan ke 5, 12 dan 15 yaitu pengiriman paket yang dilakukan oleh J\&T Express cepat dan tepat waktu sesuai dengan estimasi pengiriman, Karyawan memilikikemampuan komunikasi yang baik ketika berkomunikasi dengan pelanggan dan karyawan J\&T Express mampu memberikan pelayanan yang baik secara personal atau individu sebesar $2 \%$ atau 1 responden. Berdasarkan data tersebut dapat disimpulkan bahwa sebagai jasa pengiriman J\&T Express karyawannya mampu kerja cepat dalam melakukan tugasnya sehingga pelanggan tertarik untuk menggunakan jasa J\&T Express Garut Kota. 


\section{Variabel Keputusan Pembelian (Y)}

Sebagian besar responden memberikan jawabansetuju. Dimana hasil terbanyak setuju terdapat pada item 14 yaitu saya yakin menggunakan jasa J\&T Express karena metode pembayaran yang digunakan sangat mudah sebesar $56 \%$ atau sebanyak 28 responden. Hasil terkecil atausangat tidak setuju pada item atau pernyataan 4, 5, 12 dan 15 yaitu "Informasi dariorang lain, media massa, konsumen dan organisasi mengenai jasa J\&T Express membuat saya ingin menggunakannya", "Informasi dari iklan, Internet, web dan penyalur mengenai jasa J\&T Express membuat saya ingin menggunakannya", "J\&T Express membatasi penerimaan kuantitas barang dari konsumen" dan "saya akan menggunakan jasa J\&T Express lagi karena sudah memiliki kemantapan yang kuat pada jasa J\&T Express sebesar $2 \%$ atau 1 responden. Berdasarkan data tersebut dapat disimpulkan bahwa pengguna jasa merasa yakin dan setuju menggunakan J\&T Express karena dalam metode pembayarannya saat transaksi sangat mudah dilakukan.

\section{Uji Validitas}

Uji validitas merupakan suatu ukuran yang menunjukkan tingkat keabsahan suatu instrumen atau alat ukur. Sebuah alat ukur dikatakan valid apabila mampu mengukur apa yang diinginkan. Berdasarkan hasil pengolahan SPSS. Maka dapat dikatakan seluruh item pernyataan dikatakan valid, karena seluruh hasil koefisien korelasi lebih besar dari nilai $t_{\text {tabel. }}$. Hasil dari pengolahan data uji validitas X1, X2 dan Y dengan menggunakan program aplikasi komputer Microsoft Excel terlihat pada tabel di bawah ini:

Tabel 2 : Hasil perhitungan uji validitas brand image

\begin{tabular}{lcccc}
\hline Variabel & $\begin{array}{c}\text { No. } \\
\text { Pernyataan }\end{array}$ & $\begin{array}{c}\text { Koefisien } \\
\text { Validitas }\end{array}$ & r tabel df(N-2)=50 & Kesimpulan \\
\hline 1 & 399 & 0,2787 & Valid \\
\hline 2 & 640 & 0,2787 & Valid \\
\hline 3 & 511 & 0,2787 & Valid \\
\cline { 2 - 5 } Brand Image & 4 & 355 & 0,2787 & Valid \\
\cline { 2 - 5 } & 5 & 405 & 0,2787 & Valid \\
\cline { 2 - 5 } & 6 & 389 & 0,2787 & Valid \\
\cline { 2 - 5 } & 7 & 575 & 0,2787 & Valid \\
\cline { 2 - 5 } & 8 & 558 & 0,2787 & Valid \\
\hline 9 & 547 & 0,2787 & Valid
\end{tabular}

Sumber: Hasil Penelitian Pengolahan Data Primer (2021)

Tabel 3 : Hasil perhitungan uji validitas kualitas pelayanan

\begin{tabular}{ccccc}
\hline Variabel & $\begin{array}{c}\text { No. } \\
\text { Pernyataan }\end{array}$ & $\begin{array}{c}\text { Koefisien } \\
\text { Validitas }\end{array}$ & $\begin{array}{l}\text { r tabel df(N- } \\
\mathbf{2})=\mathbf{5 0}\end{array}$ & Kesimpulan \\
\hline 1 & .496 & 0,2787 & Valid \\
\hline 2 & .605 & 0,2787 & Valid \\
\hline 3 & .478 & 0,2787 & Valid \\
\hline 4 & .515 & 0,2787 & Valid \\
\hline 5 & .489 & 0,2787 & Valid \\
\hline 6 & .479 & 0,2787 & Valid \\
\hline 7 & .453 & 0,2787 & Valid \\
\hline
\end{tabular}




\begin{tabular}{ccccc}
\hline Variabel & $\begin{array}{c}\text { No. } \\
\text { Pernyataan }\end{array}$ & $\begin{array}{c}\text { Koefisien } \\
\text { Validitas }\end{array}$ & $\begin{array}{l}\text { r tabel df(N- } \\
\mathbf{2})=\mathbf{5 0}\end{array}$ & Kesimpulan \\
\hline \multirow{3}{*}{$\begin{array}{c}\text { Kualitas } \\
\text { Pelayanan }\end{array}$} & 8 & .577 & 0,2787 & Valid \\
\cline { 2 - 5 } & 9 & .566 & 0,2787 & Valid \\
\cline { 2 - 5 } & .550 & 0,2787 & Valid \\
\cline { 2 - 5 } & 10 & .432 & 0,2787 & Valid \\
\hline 11 & .571 & 0,2787 & Valid \\
\hline 12 & .590 & 0,2787 & Valid \\
\hline 13 & .453 & 0,2787 & Valid \\
\hline 14 & .381 & 0,2787 & Valid \\
\hline 15 & .566 & 0,2787 & Valid \\
\hline
\end{tabular}

Sumber: Hasil Penelitian Pengolahan Data Primer (2021)

Tabel 4 : Hasil perhitungan uji validitas keputusan pembelian

\begin{tabular}{|c|c|c|c|c|}
\hline Variabel & $\begin{array}{c}\text { No. } \\
\text { Pernyataan }\end{array}$ & $\begin{array}{l}\text { Koefisien } \\
\text { Validitas }\end{array}$ & $\begin{array}{l}r \text { tabel df } \\
(\mathrm{N}-2)=50\end{array}$ & Kesimpulan \\
\hline \multirow{17}{*}{$\begin{array}{l}\text { Keputusan } \\
\text { Pembelian }\end{array}$} & 1 & .512 & 0,2787 & Valid \\
\hline & 2 & .517 & 0,2787 & Valid \\
\hline & 3 & .351 & 0,2787 & Valid \\
\hline & 4 & .450 & 0,2787 & Valid \\
\hline & 5 & .464 & 0,2787 & Valid \\
\hline & 6 & .362 & 0,2787 & Valid \\
\hline & 7 & .474 & 0,2787 & Valid \\
\hline & 8 & .467 & 0,2787 & Valid \\
\hline & 9 & .540 & 0,2787 & Valid \\
\hline & 10 & .614 & 0,2787 & Valid \\
\hline & 11 & .548 & 0,2787 & Valid \\
\hline & 12 & .269 & 0,2787 & Valid \\
\hline & 13 & .468 & 0,2787 & Valid \\
\hline & 14 & .607 & 0,2787 & Valid \\
\hline & 15 & .387 & 0,2787 & Valid \\
\hline & 16 & .545 & 0,2787 & Valid \\
\hline & 17 & .486 & 0,2787 & Valid \\
\hline
\end{tabular}

Sumber: Hasil Penelitian Pengolahan Data Primer (2021)

\section{Uji Reliabilitas}

Uji Reliabilitas merupakan indeks yang menunjukkan sejauh mana alat ukurdapat dipercaya atau diandalkan. Berdasarkan hasil pengolahan spss, maka dapat dikatakan nilai reliabilitas Brand Image, Kualitas Layanan dan Keputusan Pembelian masing-masing sebesar. 
Tabel 5 : Hasil perhitungan uji reliabilitas variabel X1, X2 dan Y

\begin{tabular}{lccl}
\hline \multicolumn{1}{c}{ Variabel } & $\begin{array}{c}\text { Cronbach- } \\
\text { Alpha }\end{array}$ & Alpha & Keputusan \\
\hline \multicolumn{1}{c}{ Brand Image (X1) } & 0,793 & 0,05 & Reliabel \\
\hline $\begin{array}{l}\text { Kualitas } \\
\text { Pelayanan (X2) }\end{array}$ & 0,872 & 0,05 & Reliabel \\
\hline $\begin{array}{l}\text { Keputusan } \\
\text { Pembelian }\end{array}$ & 0,852 & 0,05 & Reliabel \\
\hline
\end{tabular}

Sumber: Hasil Penelitian Pengolahan Data Primer (2021)

Dari tabel 5 terlihat sangat jelas bahwa perhitungan hasil uji reliabilitas $\mathrm{X} 1, \mathrm{X} 2$ dan $\mathrm{Y}$ menunjukkan hasil yang sangat besar yang menunjukkan bahwa nilai Cronbach Alpha > Nilai Kritis menyiratkan bahwa hasil pilihan dinyatakan dapat diandalkan, dengan cara ini informasi survei dapat digunakan sebagai alat estimasi yang sah dalam mengeksplorasi dan dapat digunakan misalnya. untuk beberapa waktu kemudian.

\section{Analisis Data}

\section{Uji Asumsi Klasik}

Uji normalitas merupakan uji untuk menganalisis normal atau tidaknya suatu kuesioner yang dibuat. Uji normalitas ini menggunakan metode Kolmogorov-Smirnov yaitu uji normalitas menggunakan fungsi distribusi kumulatif. Nilai residual terstandarisasi berdistribusi normal jika $\mathrm{K}_{\text {hitung }}<\mathrm{K}_{\text {tabel }}$ atau nilai Sig. $>$ alpha. Hasil uji normalitas menggunakan metode KolmogorovSmirnov dapat dilihat pada tabel berikut.

Tabel 6: Uji normalitas metode Kolmogorov-Smirnov

\begin{tabular}{llc}
\hline & & $\begin{array}{c}\text { Standardized } \\
\text { Residual }\end{array}$ \\
\hline $\mathrm{N}$ & Mean & 50 \\
\hline Normal Parameters & \\
\hline & Std. Deviation & .0000000 \\
\hline Most Extreme & Absolute & .97937923 \\
\hline Differences & Positive & .098 \\
\hline Kolmogorov-Smirnov $Z$ & Negative & .098 \\
\hline Asymp. Sig. (2-tailed) & & -.081 \\
\hline Sumb & & .694 \\
\hline
\end{tabular}

Sumber: Hasil Penelitian Pengolahan Data Primer (2021)

Tabel di atas menunjukkan penyelidikan terhadap hasil yang diperoleh bahwa nilai KolmogorovSmirnov Z atau K hitung adalah 0,694 < Ktabel $(\mathrm{dL}=1,4625$, $\mathrm{dU}=1,6283)$ atau Asymp. Sig. (2tailed) adalah 0,721 > 0,05 (Alpha), maka hasilnya adalah nilai Residual Terstandar dinyatakan tersebar secara teratur atau informasi biasanya tersampaikan dan dapat digunakan dalam penyusunan informasi menggunakan strategi terukur lainnya. 
Uji multikolinieritas adalah tes yang diarahkan untuk melihat apakah ada faktor otonom dalam model saat ini. Koneksi yang sangat mengesankan adalah karena komparabilitas antara faktorfaktor bebas. Dengan berfokus pada angka VIF (Variance Inflation Factor), yang seharusnya di bawah 10, angka resistensi lebih dari 0,1. Dalam hal VIF berikutnya antara 1-10, tidak terjadi multikorelasi.

Tabel 7 : Hasil uji multikolinearita

\begin{tabular}{llcc}
\hline & Model & Collinearity Statistics \\
\cline { 2 - 3 } & Tolerance & VIF \\
\hline 1 & & \\
\cline { 2 - 3 } (Constant) & .343 & 2.919 \\
\hline Brand Image & .343 & 2.919 \\
\hline
\end{tabular}

Sumber: Hasil Penelitian Pengolahan Data Primer (2021)

Berdasarkan informasi yang ditentukan dengan menggunakan SPSS.16 nilai resistansi yang diberikan adalah 0,343 >0,10, dengan nilai VIF 2,919<10,00, sehingga cenderung disimpulkan bahwa tidak ada hubungan langsung antara faktor bebas atau tidak ada masalah dalam multikolinearitas pada model relaps.

Uji heteroskedastisitas adalah suatu uji yang dilakukan dengan melihat perbedaan variance residualpada suatu waktu pengamatan yang lainnya. Dengan melihat pola dari gambar Scatterplot, bisa diketahui ada dan tidaknya heteroskedestisitas pada suatu model. Jika titik-titik dari data yang dihasilkan menyebar diatas dan dibawah disekitar angka 0, maka tidak mengalami heteroskedastisitas pada regersi tersebut. Selain itu titi ini harus menyebar tidak hanya berkumpul dibawah atau diatas, tidak juga penyebaran titik-titik ini membentuk gelombang dan pola.

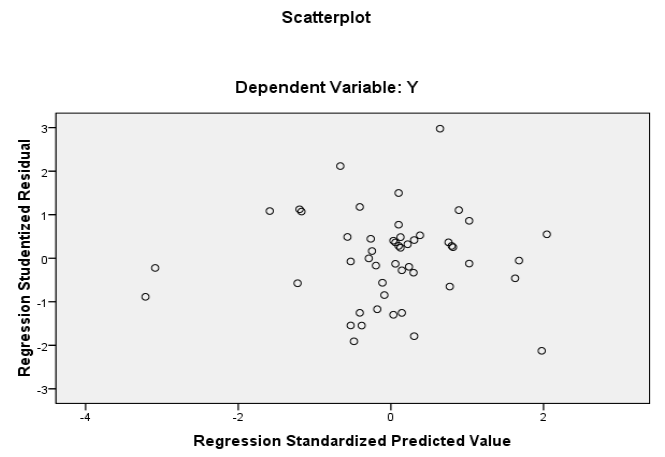

Gambar 1: Hasil uji heteroskedastisitas

Sumber: Hasil Penelitian Pengolahan Data Primer (2021)

Berdasarkan hasil perhitungan diatas dapat diketahui bahwa tanda titik pada uji yang dihasilkan tidak membentuk/menghasilkan sebuah gelombang maupun contoh yang tidak salah lagi, terlihat bahwa setiap titik berikutnya di bawah angka 0 pada hub Y menyebar. Hal ini cenderung dianggap bahwa dalam model relaps ini tidak ada masalah dengan heteroskedastisitas.

Uji autokorelasi merupakan Suatu uji yang dilakukan pada sebuah model regresi linier untuk mengetahui ada dan tidaknya hubungan atau korelasi antara kesalahan pengganggu pada periode t dengan kesalahan pengganggu periode sebelumnya. Pada uji autokorelasi dalam penelitian ini penulis menggunakan uji Durbin Watson. Berikut hasil uji autokorelasi: 
Tabel 8 : Hasil uji autokorelasi

\begin{tabular}{cccccc} 
Model & $\boldsymbol{R}$ & $\boldsymbol{R}$ Square & Adjusted $\boldsymbol{R}$ Square & $\begin{array}{c}\text { Std. Error of the } \\
\text { Estimate }\end{array}$ & $\begin{array}{c}\text { Durbin- } \\
\text { Watson }\end{array}$ \\
\hline 1 & $.871^{\mathrm{a}}$ & .758 & .748 & 4.161 & 1.678 \\
\hline
\end{tabular}

Sumber: Hasil Penelitian Pengolahan Data Primer (2021)

Berdasarkan informasi hasil diatas, harga Durbin Watson adalah 1,678, korelasi menggunakan nilai kepentingan 5\%, jumlah tes adalah $50(\mathrm{n})$, dan jumlah faktor otonom adalah $2(\mathrm{k}=2)$, maka, maka tabel Durbin Watson akan mendapatkan nilai du 1,628. Mengingat nilai DW sebesar 1,678 yang lebih tinggi dari sejauh mungkin (du) sebesar 1,628 dan lebih rendah dari 4 - 1,628 (2,372), cenderung dianggap tidak ada masalah dan autokorelasi positif.

\section{Uji Hipotesiss}

\section{Analisis Regresi Linear Berganda}

Analisis yang digunakan untuk menguji hipotesis dalam penelitian inimenggunakan analisis regresi linear berganda. Regresi linear berganda digunakanuntuk mengetahui pengaruh variabel independen (Brand Image, Kualitas Pelayanan) terhadap variabel dependen (Keputusan Pembelian).

Tabel 9: Hasil uji regresi linear berganda

Coefficients $^{a}$

\begin{tabular}{|c|c|c|c|c|c|}
\hline \multirow[t]{2}{*}{ Model } & \multicolumn{2}{|c|}{$\begin{array}{c}\text { Unstandardized } \\
\text { Coefficients }\end{array}$} & \multirow{2}{*}{$\begin{array}{c}\text { Standardized } \\
\text { Coefficients }\end{array}$} & \multirow[t]{2}{*}{$t$} & \multirow[t]{2}{*}{ Sig } \\
\hline & $B$ & Std. Error & & & \\
\hline 1 (Constant) & 6.644 & 5.019 & & 1.324 & 192 \\
\hline 'Brand Image & .490 & 209 & .288 & 2.345 & .023 \\
\hline Kualitas Pelayanan & 673 & .133 & 621 & 5.066 & .000 \\
\hline
\end{tabular}

Sumber: Hasil Penelitian Pengolahan Data Primer (2021)

Persamaan regresi yang didapat dari hasil perhitungan adalah sebagai berikut:

$$
\mathrm{Y}=6,644+0,490 \mathrm{X} 1+0,673 \mathrm{X} 2
$$

Dimana:

$\mathrm{Y}:$ keputusan Pembelian

$\mathrm{X} 1$ : Brand Image

$\mathrm{X} 2$ : Kualitas Pelayanan

\section{Uji Koefisien Determinasi (R2)}

Koefisien determinasi adalah tes untuk menyelidiki kapasitas model yang digunakan dalam mengklarifikasi berbagai faktor otonom pada faktor. Nilai R2, yang menyiratkan kapasitas faktor 
bebas untuk bergerak menuju variabel, dapat meneruskan hampir semua data yang diharapkan dalam hasil variabel yang dinilai. Hasilnya dapat ditemukan pada tabel terlampir.

Tabel 10 : Hasil koefisien determinasi

\begin{tabular}{ccccc} 
Model & $\boldsymbol{R}$ & $\boldsymbol{R}$ Square & Adjusted RSquare & $\begin{array}{l}\text { Std. Error ofthe } \\
\text { Estimate }\end{array}$ \\
\hline 1 & $.871^{\mathrm{a}}$ & .758 & .748 & 4.161 \\
\hline
\end{tabular}

Sumber: Hasil Penelitian Pengolahan Data Primer (2021)

Mengingat efek samping dari uji Koefisien Determinasi (R2) seperti yang ditampilkan pada tabel di atas, ukuran koefisien penjaminan atau Adjusted R Square adalah 74,8. Ini menyiratkan bahwa $74,8 \%$ dari faktor pilihan ini dipengaruhi dan dapat diklarifikasi melalui faktor citra merek dan kualitas pelayanan, sedangkan sisanya $25,2 \%$ dijelaskan oleh berbagai faktor di luar situasi di atas.

\section{Uji f (Simultan)}

Uji f merupakan uji yang dilakukan sekaligus untuk mengukur pengaruh antara variabel otonom dan variabel terikat dengan mempertimbangkan nilai kemungkinan (sig) pada hasil SPSS. Dalam uji sinkron ini terdapat beberapa pengaturan, untuk lebih spesifiknya cenderung dikatakan memiliki pengaruh yang bersamaan antara variabel citra merek (X1) dan kualitas pelayanan (X2) terhadap variabel pilihan pembelian (Y). Jika nilai Fhitung > Ftabel, namun dengan asumsi nilai Fhitung < Ftabel, maka tidak ada pengaruh antara variabel citra merek (X1) dan kualitas pelayanan (X2) terhadap variabel pilihan pembelian (Y) secara bersamaan waktu. Pengujian sinkron pada proposisi ini memanfaatkan SPSS 16.0 for windows. Konsekuensi dari uji F dapat ditemukan dalam hasil ANOVA yang menyertainya.

Tabel 11: Hasil uji f (simultan)

\begin{tabular}{|c|c|c|c|c|c|c|}
\hline \multicolumn{7}{|c|}{$A N O V A^{b}$} \\
\hline & Model & $\begin{array}{l}\text { Sum of } \\
\text { Squares }\end{array}$ & $d f$ & $\begin{array}{c}\text { Mean } \\
\text { Square }\end{array}$ & $F$ & Sig. \\
\hline \multirow[t]{3}{*}{1} & \multirow{3}{*}{$\begin{array}{c}\text { Regression } \\
\text { Residual } \\
\text { Total }\end{array}$} & 2548.604 & 2 & 1274.302 & 73.587 & $.000^{\mathrm{a}}$ \\
\hline & & 813.896 & 47 & 17.317 & & \\
\hline & & 3362.500 & 49 & & & \\
\hline
\end{tabular}

Sumber: Hasil Penelitian Pengolahan Data Primer (2021)

Berdasarkan data hasil hitungan statistik diatas, bahwa nilai Fhitung yang didapatkan adalah 73,587 sedangkan untuk Ftabel nya adalah 3,20. Maka hal tersebut sangat mungkin beralasan bahwa citra merek dan kualitas administrasi keduanya memengaruhi pilihan pembelian

\section{Pengaruh brand image Keputusan Pembelian Jasa J\&T Express}

Hasil Uji Hipotesis menunjukkan bahwa Brand Image (citra merek) berpengaruh signifikan terhadap keputusan pembelian jasa di perusahaan J\&T Express. Hal ini dibuktikan dengan hasil uji $\mathrm{t}$ (parsial) yaitu $\mathrm{t}_{\text {hitung }}(2,345)>\mathrm{t}_{\text {tabel }}(1,678)$ dengan nilai $(\mathrm{Sig} 0,023<0,05) \mathrm{maka}_{0}$ ditolak dan Ha diterima sehinggadapat disimpulkan bahwa variabel independen yaitu (X1) brand image 
berpengaruh positif dan signifikan terhadap variabel dependen yaitu keputusan pembelian (Y) jasa. Sedangkan nilai uji $\mathrm{f}$ (simultan) yaitu $\mathrm{f}_{\text {hitung }}(73,587)>\mathrm{f}_{\text {tabel }}(3,20)$ yang berarti variabel brand image dan kualitas layanan berpengaruh secara simultan (bersamaan) terhadap keputusan pembelian jasa.

Diketahui bahwa besar koefisien determinasi atau kemampuan brand image (X1) dalam menjelaskan atau memprediksi variabel keputusan pembelian jasa (Y) sebesar 0,748. Hal ini menunjukkan bahwa persentase gabungan variabel independen brand image terhadap variabel keputusan pembelian jasa sebesar 74,8\%. sedangkan sisanya $(100 \%-74,8 \%)=25,2 \%$ dipengaruhi oleh variabel lain yang tidak dimasukkan dalam penelitian ini.

\section{Pengaruh Kualitas Pelayanan Terhadap Keputusan Pembelian Jasa J\&T Express}

Hasil Uji Hipotesis menunjukkan bahwa kualitas pelayanan berpengaruh signifikan terhadap keputusan pembelian jasa di perusahaan J\&T Express. Hal ini dibuktikan dengan hasil uji t (parsial) yaitu $\mathrm{t}_{\text {hitung }}(5,066)>\mathrm{t}_{\text {tabel }}(1,678)$ dengan nilai $(\mathrm{Sig} 0,000<0,05)$ maka $\mathrm{H}_{0}$ ditolak dan Ha diterima sehingga dapat disimpulkan bahwa variabel independen yaitu (X2) kualitas pelayanan berpengaruh positif dan signifikan terhadap variabel dependen yaitu (Y) keputusan pembelian jasa. Sedangkan nilai uji $\mathrm{f}$ ( simultan) yaitu $\mathrm{f}_{\text {hitung }}(73,587)>\mathrm{f}_{\text {tabel }}(3,20)$ yang berarti variabel brand image dan kualitas layanan berpengaruh secara simultan (bersamaan) terhadap keputusan pembelian jasa.

Diketahui bahwa besar koefisien determinasi atau kemampuan kualitas pelayanan (X2) dalam menjelaskan atau memprediksi variabel keputusan pembelian jasa (Y) sebesar 0,748. Hal ini menunjukkan bahwa persentase sumbangan variabel independen keputusan pembelian terhadap variabel keputusanpembelian jasa sebesar 74,8\%. sedangkan sisanya $(100 \%-74,8 \%)=$ $25,2 \%$ dipengaruhi oleh variabel lain yang tidak dimasukkan dalam penelitian ini.

\section{Pengaruh Citra Merek dan Kualitas Pelayanan Terhadap Keputusan Pembelian Jasa J\&T Express}

Hasil Uji Hipotesis menunjukkan bahwa Brand Image (citra merek) danKualitas Pelayanan berpengaruh signifikan terhadap keputusan pembelian jasa di perusahaan J\&T Express. Hal ini dibuktikan dengan hasil uji t (parsial) Brand Image yaitu thitung $(2,345)>t_{\text {tabel }}(1,678)$ dengan nilai (Sig $0,023<0,05)$, hasil ujit (parsial) yaitu $t_{\text {hitung }}(5,066)>t_{\text {tabel }}(1,678)$ dengan nilai (Sig $0,000<0,05)$ maka $\mathrm{H}_{0}$ ditolak dan Ha diterima sehingga dapat disimpulkan bahwa variabel independen yaitu (X1) brand image dan (X2) kualitas pelayanan berpengaruh positif dan signifikan terhadap variabel dependen yaitu $(\mathrm{Y})$ keputusan pembelian jasa. Sedangkan nilai uji $\mathrm{f}$ (simultan) yaitu $f_{\text {hitung }}(73,587)>f_{\text {tabel }}(3,20)$ yangberarti variabel brand image dan kualitas layanan berpengaruh secara simultan (bersamaan) terhadap keputusan pembelian jasa.

Diketahui bahwa besar koefisien determinasi atau kemampuan brand image (X1) dan keputusan pembelian (X2) dalam menjelaskan atau memprediksi variabel keputusan pembelian jasa (Y) sebesar 0,748 . Hal ini menunjukkan bahwapersentase sumbangan variabel independen keputusan pembelian terhadap variabel keputusan pembelian jasa sebesar 74,8\%. sedangkan sisanya $(100 \%-74,8 \%)=25,2 \%$ dipengaruhi oleh variabel lain yang tidak dimasukkan dalam penelitian ini. 


\section{Simpulan dan Saran}

Berdasarkan hasil penelitian ini dan pembahasan maka dari itu dapat ditarik kesimpulan yaitu:

1. Hasil Penelitian menunjukan bahwa brand Image (X1) berpengaruh positif secara signifikan terhadap keputusan pembelian jasa. Variabel Brand Image memiliki nilai $\mathrm{F}_{\text {hitung }}$ $>\mathrm{F}_{\text {tabel }}$ maka $\mathrm{H}_{0}$ ditolak karena $\mathrm{F}_{\text {tabel }}$ lebih besar $\mathrm{F}_{\text {hitung, }}$, Ha dikarena sehingga variabel Brand Image berpengaruh positif dan signifikan terhadap variabel keputusan pembelian jasa. Artinya jika perusahaan mampu memberikan Brand Image yang baik secara langsung terhadap pelanggan, karena Brand Image menjadi salah satu keputusan penting bagi pelanggan untuk dapat meningkatkan pengelolaan merek menjadi salah satu keputusan penting bagi pelanggan untuk pengelolaan merek menjadi lebih baik agar dapat memuaskan konsumen.

2. Hasil penelitian menunjukan bahwa variabel (X2) kualitas penelitian layanan berpengaruh positif terhadap keputusan pembelian jasa, variabel kualitas layanan memiliki nilai $t_{\text {hitung }}>$ $\mathrm{t}_{\text {tabel }}$ maka $\mathrm{H}_{0}$ ditolak dan $\mathrm{Ha}$ diterima sehingga variabel kualitas layanan berpengaruh sigfinikan terhadap variabel keputusan pembelian jasa. Artinya kualitas layanan dilihat dari pengalaman yang berkesan bagi pelanggan dapat dijadikan perusahaan sebagai kekuatan untuk menarik konsumen potensial, untuk mempertahankan pelanggan yang ada.

3. Brand Image dan kualitas pelayanan berpengaruh terhadap keputusan pembelian jasa berpengaruh positif dan simultan terhadap keputusan pembelian jasa J\&T Exspress. Artinya pelanggan merasa puas berdasarkan brand image dan kualitas pelayanan mereka akan melakukan keputusan pembelian positif, sebaliknya jika pelanggan merasa tidak puas atas brand image dan kualitas pelayanan maka pelanggan akan melakukan keputusan pembelian negatif.

Maka dari itu, saran yang dapat diberikan diantaranya:

1. Berusaha untuk terus mempertahankan serta meningkatkan brand image perusahaan melalui produk-produk yang ditawarkan kepada konsumen, mengingat brand image dapat menentukan keputusan pembelian.

2. Penggunaan alat dan media marketing harus sesuai dalam meningkatkan brand atau citra di pandangan publik atau konsumen, seperti pengiklanan melalui website, dengan tujuan supaya masyarakat lebih tahu dan kenal tentang J\&T Express.

3. Membuat suatu inovasi yang mampu menimbulkan kesan yang baik atau positif di ingatan para konsumen.

4. Menawarkan kelebihan-kelebihan yang dimiliki J\&T Express yang tidak dimiliki oleh perusahaan lain. Misalnya harga pengiriman, pelayanan, fasilitas dll, sehingga mampu meningkatkan peminat dan penggunaan jasanya.

\section{Daftar Pustaka}

Audina,R \& M.A.A, Murtani (2019). Pengaruh Kualitas Layanan, Brand Image, Harga dan Promosi terhadap Keputusan Menggunakan Jasa Laundry Syar'i. Jurnal FEB, Vol.1 No. 1.

Chandra,A.P \& T, Santoso (2019) Pengaruh Brand Image, Kualitas Produk dan Harga terhadap Keputusan Pembelian di Outlet Mini Melts Surabaya. Jurnal AGORA. Vol. 7, No. 1.

Endriani, D (2018) Pengaruh Brand Image dan Service Quality Terhadap Keputusan Pembelian Jasa Dalam Perspektif Ekonomi Syariah (Studi Pada Pengguna Jasa J\&T Express Di Bandar Lampung). 
Kotler, Philip \& Gerry Armstrong, (2014): Principle Of Marketing, 15th edition. New Jersey: Pearson Pretice Hall.

Kotler, Philip and Kevin Lane Keller, 2016. Marketing Management, 15th Edition, Pearson Education,Inc.

Lupiyoadi, Rambat. 2013. Manajemen Pemasaran Jasa Berbasis Kompetensi (Edisi 3). Jakarta: Salemba Empat

Tjiptono, F (2010) Strategi Pemasaran, Andi, Yogyakarta. 